Ferrata Storti Foundation

\title{
Distal and proximal hypoxia response elements co-operate to regulate organ-specific erythropoietin gene expression
}

\author{
Ilaria M. C. Orlando, ${ }^{1,2}$ Véronique N. Lafleur, ${ }^{3}$ Federica Storti, ${ }^{1,2}$ \\ Patrick Spielmann,,$^{1,2}$ Lisa Crowther, ${ }^{1,2}$ Sara Santambrogio,,$^{1,2}$ \\ Johannes Schödel, ${ }^{4}$ David Hoogewijs, ${ }^{2,5}$ David R. Mole ${ }^{3}$ \\ and Roland $\mathrm{H}$. Wenger ${ }^{1,2}$
}

Haematologica 2020

Volume 105(12):2774-2784

${ }^{1}$ Institute of Physiology, University of Zürich, Zürich, Switzerland; ${ }^{2}$ National Center of

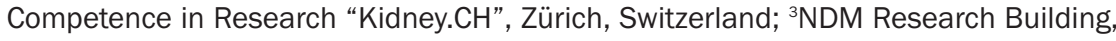
University of Oxford, Oxford, UK; ' ${ }^{4}$ epartment of Nephrology and Hypertension, Universitätsklinikum Erlangen, Friedrich-Alexander-Universität Erlangen-Nürnberg, Erlangen, Germany and ${ }^{5}$ Department of Medicine/Physiology, University of Fribourg, Fribourg, Switzerland

\section{ABSTRACT}

W Thile it has been well-established that distal hypoxia response elements (HRE) regulate hypoxia-inducible factor (HIF) target genes such as erythropoietin (Epo), an interplay between multiple distal and proximal (promoter) HRE has not yet been described. Hepatic Epo expression is regulated by an HRE located downstream of the EPO gene, but this 3 ' HRE is not essential for renal EPO gene expression. We previously identified a 5' HRE and could show that both HRE direct exogenous reporter gene expression. Here, we show that, whereas in hepatic cells the 3 ' but not the 5' HRE is required, in neuronal cells both the 5' and 3' HRE contribute to endogenous Epo induction. Moreover, two novel putative HRE were identified in the EPO promoter. In hepatoma cells, HIF interacted mainly with the distal 3' HRE, but in neuronal cells, HIF most strongly bound the promoter, bound to a lesser extent the 3' HRE, and did not bind the 5' HRE. Interestingly, mutation of either of the two distal HRE abrogated HIF binding to the $3^{\prime}$ and promoter HRE. These results suggest that a canonical functional HRE can recruit multiple transcription factors (not necessarily HIF) to mediate HIF binding to different distant HRE in an organ-specific manner.

\section{Correspondence:}

ROLAND H. WENGER

roland.wenger@access.uzh.ch

Received: August 27, 2019.

Accepted: December 18, 2019.

Pre-published: December 19, 2019.

doi:10.3324/haematol.2019.236406

(C)2020 Ferrata Storti Foundation

Material published in Haematologica is covered by copyright. All rights are reserved to the Ferrata Storti Foundation. Use of published material is allowed under the following terms and conditions:

https://creativecommons.org/licenses/by-nc/4.0/legalcode. Copies of published material are allowed for personal or internal use. Sharing published material for non-commercial purposes is subject to the following conditions:

https://creativecommons.org//icenses/by-nc/4.0/legalcode, sect. 3. Reproducing and sharing published material for commercial purposes is not allowed without permission in writing from the publisher.

\section{Introduction}

Erythropoietin (Epo) is essential for the maintenance of a normal blood oxygen concentration and Epo synthesis is induced under anemic and hypoxic conditions. ${ }^{1,2}$ In the adult, Epo production by the kidney and liver accounts for approximately $90 \%$ and $10 \%$, respectively, of total circulating Epo, but ectopic Epo expression was also found in the brain, uterus and testis, among others, where it is thought to have pleiotropic, organ-restricted and tissue protective functions. ${ }^{3-6}$ Renal Epo is synthesized by peritubular pericytes with fibroblastic and neuronal features, located in the juxtamedullary cortex.-9 These cells respond to a decrease in tissue oxygen partial pressure by hypoxia-inducible factor (HIF)-2 $\alpha$ stabilization and HIF-2dependent transcriptional induction of $E P O$ gene expression. ${ }^{10} \mathrm{HIF}$ bind to a hypoxia response element (HRE) containing the essential core consensus sequence 5'-RCGTG-3' which, however, is not sufficient to confer hypoxia-inducible gene expression. ${ }^{11}$ Distinct regulatory DNA elements enhance EPO promoter activity in liver and kidney. Transgenic mouse models showed that in the liver, $0.7 \mathrm{~kb}$ of the immediate 3 '-flanking region is required, whereas in the kidney, the essential regulatory element resides between -14 and $-6 \mathrm{~kb}$ in the distal $5^{\prime}$-region. ${ }^{12-15}$ The $3^{\prime}$ HRE is well established and has been shown to be necessary and sufficient for liver-specific EPO gene expression after embryonic day 14.5. ${ }^{16,17}$ However, the DNA element responsible for kidney-specific EPO gene expression has been far less well characterized and nothing is known about the endogenous HRE in Epo-producing cells of other tissues.

We recently discovered a strongly conserved distal 5' HRE and suggested that it 
might contribute to oxygen-regulated EPO expression. ${ }^{18}$ This 5' HRE resides within a DNaseI hypersensitive site $9.2 \mathrm{~kb}$ upstream of the EPO transcriptional start site, contains both the 5'-ACGTG-3' core HIF DNA binding site as well as the ancillary 5'-CACA-3' element, ${ }^{11}$ and confers hypoxia-inducible exogenous reporter gene expression in Epo expressing and non-expressing cell lines. ${ }^{18}$ However, the organ-specific relevance of the endogenous $5^{\prime}$ and $3^{\prime}$ HRE, as well as their functional interaction with the EPO promoter, remained unknown. Considering the neuronal features that we and others reported for the renal Epo-producing cells, ${ }^{8,9}$ we therefore analyzed the relative contribution of the 5' and 3' HRE in Kelly cells, a human neuroblastoma cell line that has previously been shown to regulate the EPO gene in an oxygen and HIF-dependent manner. ${ }^{19}$ Endogenous HRE function was investigated by gene editing and HIF-DNA interaction studies. Intriguingly, novel promoter HRE were identified and profound differences in the functional co-operation between the 5', 3' and promoter HRE in Kelly cells were found when compared with the well-established human Hep3B hepatoma cell model. ${ }^{20}$

\section{Methods}

\section{Cell culture}

Human Hep3B and HepG2 hepatocellular carcinoma (American Type Culture Collection, LGC Standards, Wesel, Germany) and Kelly neuroblastoma (kindly provided by J. Fandrey, Essen, Germany) cell lines were cultured in high glucose Dulbecco's modified Eagle's medium (DMEM) and RPMI-1640 medium, respectively (Sigma Aldrich, Saint Louis, MO, USA), supplemented with $10 \%$ heat-inactivated fetal bovine serum (Thermo Fisher Scientific, Waltham, MA, USA), $50 \mathrm{IU} / \mathrm{mL}$ penicillin and $50 \mu \mathrm{g} / \mathrm{mL}$ streptomycin (Sigma Aldrich). Cells were exposed to hypoxic conditions using a workstation as previously described. ${ }^{21}$

\section{Gene editing}

Clustered regularly interspaced short palindromic repeats (CRISPR)/CRISPR-associated 9 (Cas9) gene editing was performed as reported $\mathrm{d}^{22}$ and is described in detail in the Online Supplementary Methods.

\section{RNA and protein analyses}

RNA was extracted and quantified by reverse-transcription (RT) real-time quantitative (q) polymerase chain reaction (PCR) as previously described. ${ }^{21,23}$ In brief, RT was performed with $2 \mu \mathrm{g}$ total RNA and AffinityScript reverse transcriptase (Agilent), and the cDNA quantified using SYBR Green qPCR reagent kit (Kapa Biosystems, London, UK) in a MX3000P light cycler (Agilent). Transcripts levels were calculated through comparison with calibrated standard curves and normalized to human ribosomal protein L28 mRNA. Primers used for RT-qPCR are listed in Online Supplementary Table S1. Epo protein was detected by ELISA according to the manufacturer's protocol (R\&D Systems, Minneapolis, MN, USA). Immunoblotting was performed as previously described ${ }^{21}$ using the following primary antibodies: mouse monoclonal anti-HIF-1 $\alpha$ (\#610959; BD Transduction Laboratories, San Jose, CA, USA), rabbit monoclonal anti-HIF$2 \alpha$ (\#PAB12124; Abnova, Taipei, Taiwan), mouse monoclonal anti-HIF- $\beta$ (D28F3; Cell Signaling Technology, Danvers, MA, USA), mouse monoclonal anti- $\beta$-actin (A5441; Sigma Aldrich). Secondary antibodies were HRP-conjugated goat polyclonal anti-rabbit or anti-mouse IgG (\#31460 and \#31430, respectively; Thermo Fisher Scientific).

\section{Luciferase reporter gene assays}

Reporter gene constructs have been described previously. ${ }^{18}$ Canonical 5'-RCGTG-3' HRE were replaced by 5'-RAAAG-3' using site-directed mutagenesis. Following transfection with lipofectamine, cells were incubated under normoxic or hypoxic $(0.2 \%$ $\mathrm{O}_{2}$ ) conditions for 24 hours (h). Reporter gene assays were performed as described before ${ }^{21}$ using a luciferase assay kit (Promega, Madison, WI, USA). Luciferase activity was normalized to the protein content as determined by the Bradford assay. ${ }^{24}$

\section{Hypoxia-inducible factor chromatin immunoprecipitation}

Chromatin immunoprecipitation (ChIP) experiments were performed as described previously, ${ }^{21,25,26}$ using the following rabbit polyclonal antibodies: anti-HIF-1 $\alpha$ (PM14), anti-HIF-2 $\alpha$ (PM9), anti-HIF- $\beta$ (NB100-110; Novus Biologicals, Littleton, CO, USA), normal rabbit serum (X0902; Dako, Glostrup, Denmark). Co-precipitated DNA was quantified by real-time qPCR using the primers listed in Online Supplementary Table S1.

\section{Statistical analysis}

All data are shown as mean+standard error of mean. Unpaired two-tailed Student $t$-tests were applied. $P<0.05$ was considered statistically significant.

\section{Results}

\section{Mutation of the EPO 5' and 3' hypoxia response elements by gene editing}

CRISPR-Cas9 technology was used for the specific destruction of the endogenous EPO HRE to dissect the relative contribution of the $-9.2 \mathrm{~kb} 5^{\prime}$ HRE and the $+3.0 \mathrm{~kb} 3^{\prime}$ HRE to hypoxia-inducible EPO gene expression in neuronal and hepatic cell lines (Figure 1A). sgRNAs were designed to target the HIF-binding core sequence 5'ACGTG-3' (Figure 1B). ${ }^{11}$ The restriction enzyme Tail was used to assess the presence of the $5^{\prime}$-ACGT-3' sequence. ${ }^{27}$ Successful HRE destruction confers Tail resistance to the PCR products as exemplified for Kelly cells in Figure 1C and D. Monoclonal cell lines were obtained by limiting dilution cloning of initial partially gene edited polyclonal cell pools. The HRE regions were again amplified by PCR, re-tested for complete Tail resistance, and cloned into plasmid vectors. Multiple independent plasmids were sequenced to ensure biallelic HRE inactivation. Alternatively, amplicons were directly deep sequenced. Clone verification and sequence information is provided in Online Supplementary Figure S1. Note that, in some cases (Kelly-3'B2, Hep3B-5'H11), more than two mutant alleles were detected, which may be due to either polyclonal cell lines, polyploidy, gene amplification or genetic drift. Other clones maintained wild-type HRE sequences (Kelly5'C4, Kelly-3'C4, Hep3B-5'A5, HepG2-5'H8, HepG23'D6; confirmed by sequencing of PCR products) and were included as additional controls in subsequent experiments.

\section{The 5' hypoxia response element contributes to hypoxic EPO induction in neuronal but not hepatic cells}

The neuroblastoma cell line Kelly has been reported to induce endogenous Epo mRNA levels, at $24 \mathrm{~h}$, by more than 71 -fold under hypoxic conditions $\left(3 \% \mathrm{O}_{2}\right)$ and more than 238 -fold under anoxic conditions. ${ }^{19}$ Kelly cells therefore recapitulate the well-known hypoxia-inducible EPO 
A

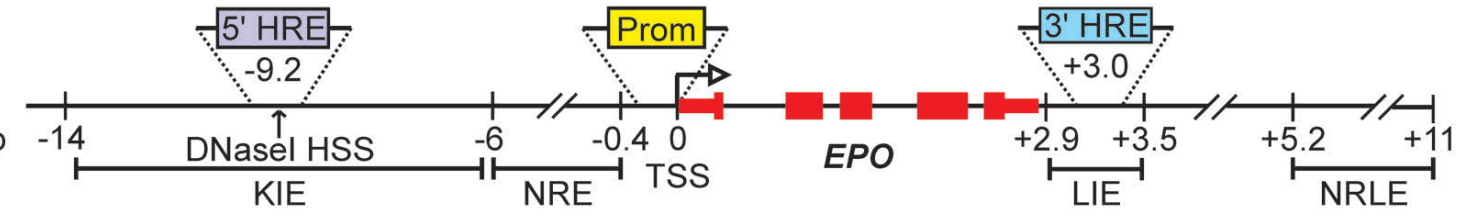

B

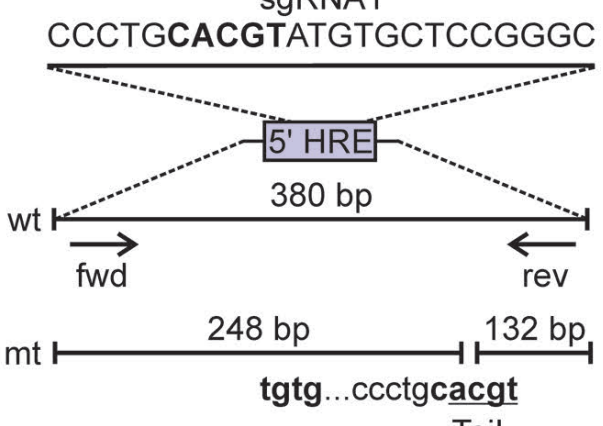

Tail

C

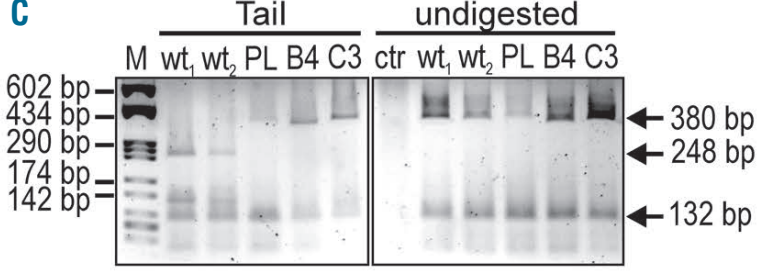

5' HRE gene editing (Kelly)
sgRNA2

CCCTACGTGCTGTCTCACACAGC

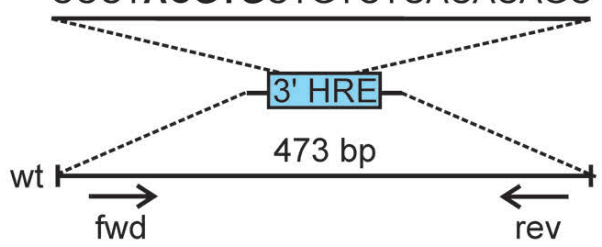

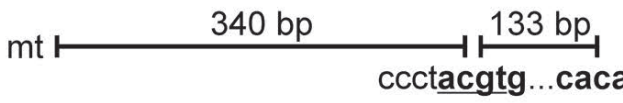

Tail

D Tail $\quad$ undigested

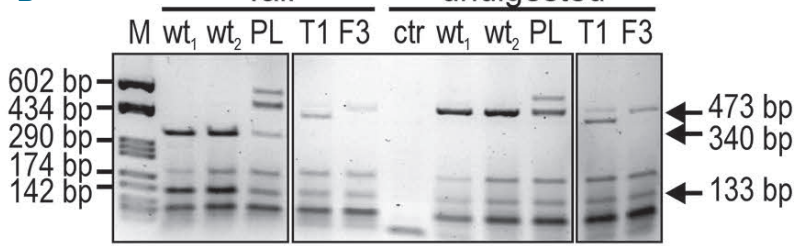

3' HRE gene editing (Kelly)

Figure 1. EPO 5' and 3' hypoxia response elements (HRE) gene editing. (A) Scheme depicting the human EPO locus. HSS: hypersensitivity site; TSS: transcriptional start site; KIE: kidney inducible element; NRE: negative regulatory element; LIE: liver inducible element; NRLE: negative regulatory liver element. (B) Single-guided (sg) RNA sequences designed to target the EPO 5' and 3' HRE by CRISPR-Cas9. In bold: consensus HIF binding site; arrows: polymerase chain reaction (PCR) primers used to amplify the HRE regions; fwd: forward; rev: reverse; wt: wild-type; mt: mutant. Mutation of the consensus HRE confers resistance to Tail restriction digestion as shown by agarose gel analysis of digested or undigested PCR products using as template genomic DNA isolated from Kelly neuroblastoma cells following $5^{\prime}$ (C) or 3' (D) HRE gene editing. M: marker; PL: polyclonal pool of cells; B4 and C3: 5' HRE mutant clones; T1 and F3: 3' HRE mutant clones; ctr: non-template control.

gene expression in the brain. ${ }^{4}$ Epo mRNA and secreted protein were induced by 1,603 -fold and 22 -fold, respectively, following exposure of wild-type Kelly cells to hypoxia $\left(0.2 \% \mathrm{O}_{2}\right)$ for $24 \mathrm{~h}$ (Figure 2). However, due to the very low basal Epo transcript levels, the fold induction factor is subject to variation and must be interpreted with caution. Indeed, the wild-type HRE subclones Kelly-5'C4 and Kelly-3'C4 showed reduced Epo mRNA induction, even though the hypoxic Epo mRNA levels were not significantly different from the maternal Kelly cells (Figure $2 \mathrm{~A})$. These results were confirmed on the protein level where the normoxic levels also varied greatly but the hypoxic levels were indistinguishable from the maternal cell line (Figure 2B). Therefore, only hypoxic Epo levels were considered for subsequent analyses.

Interestingly, all mutant 5' and $3^{\prime}$ HRE Kelly clones showed significantly reduced hypoxic Epo expression, on the mRNA (Figure 2A) as well as on the protein (Figure 2B) level. This is in striking contrast to mutant Hep3B (Figure 2C and D) and HepG2 (Figure 2E) clones where only 3' but not 5' HRE mutations strongly reduced hypoxic Epo mRNA and protein levels. Note that while Kelly and Hep3B cells were exposed to hypoxia for $24 \mathrm{~h}$, HepG2 cells showed maximal Epo mRNA induction already after 8 h, with approximately 10-fold lower mRNA levels, which was not sufficient for detectable Epo protein accu- mulation in the supernatant. To ensure that no general offtarget effects caused these results, the mRNA levels of the HIF-1 and HIF-2 target genes CAIX and LOXL2 (Kelly) or PAI1 (Hep3B and HepG2), respectively, ${ }^{28}$ were measured in the same samples. EPO HRE mutations did not significantly reduce the expression of these genes under hypoxic conditions (Online Supplementary Figure S2). Moreover, also hypoxic HIF-1 $\alpha$ and HIF- $2 \alpha$ protein stabilization was not altered by the EPO HRE mutations (Online Supplementary Figure S3). These results suggest that both the $5^{\prime}$ and $3^{\prime}$ HRE contribute to hypoxia-inducible EPO gene expression in neuronal cells whereas in hepatic cells only the $3^{\prime}$ HRE is required.

\section{5' and 3' EPO hypoxia response elements co-operatively enhance hypoxic reporter gene expression in neuronal cells}

We had previously shown that the EPO 5' HRE confers hypoxia-inducible expression to a heterologous SV40 promoter-driven reporter gene in both Hep3B and Kelly cells. ${ }^{10}$ These results stand in apparent contrast to the $5^{1}$ HRE mutation data presented above and imply differences between exogenous bacterial reporter gene plasmids and endogenous chromatin regulation. In fact, similar reporter gene results have been obtained even in non-Epo-expressing HeLa and HK-2 cells ${ }^{18}$ as well as in Hek293 and CHO 

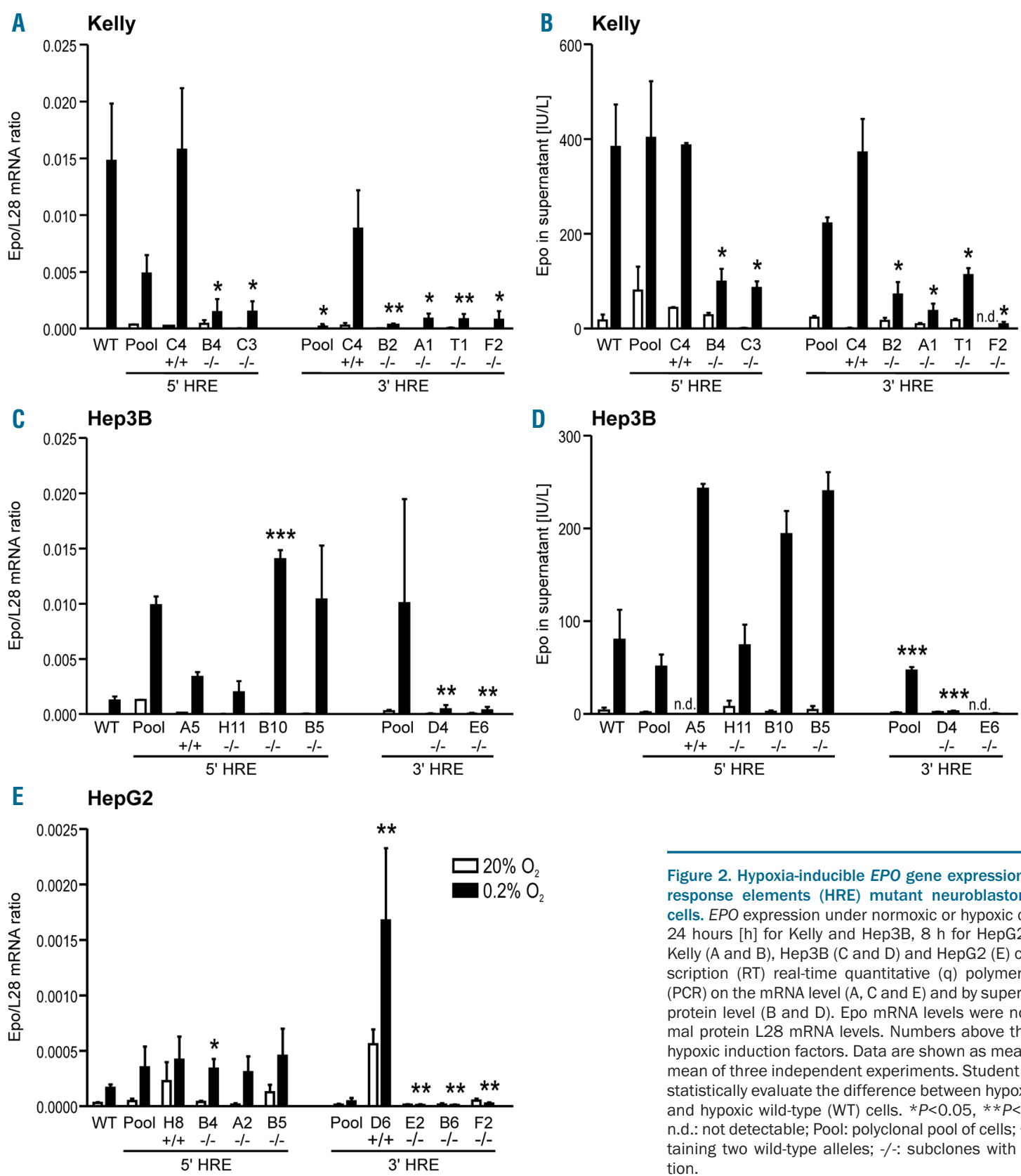

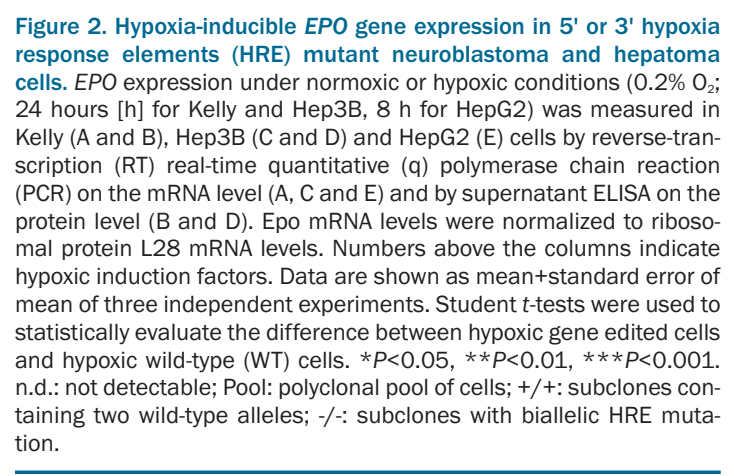

cells (data not shown). We therefore expanded these experiments by transiently transfecting Kelly cells with minimal (138 bp) EPO promoter-driven reporter genes, enhanced by various DNA fragments containing the $5^{\prime}$ and/or $3^{\prime}$ HRE. In contrast to our previous results obtained with Hep3B cells, ${ }^{18}$ EPO promoter-driven luciferase activity in Kelly cells was significantly further increased when the $100 \mathrm{bp}$ fragment containing the 5' HRE was combined with a 126 bp fragment containing the $3^{\prime}$ HRE (Figure 3A). While a longer $3 \mathrm{~kb}$ DNA fragment containing the 5' HRE reduced both hypoxic and normoxic reporter gene expression driven by the EPO promoter/3' HRE, it actually led to even higher hypoxic induction factors. These data imply co-operation between the EPO 5' and 3' HRE specifically in neuronal cells, and suggest that additional distal and proximal 5' flanking elements contribute to tissue-specific and conditional EPO regulation.

\section{A novel EPO promoter hypoxia response element contributes to hypoxic reporter gene expression in neuronal cells}

Interestingly, a slight but significant hypoxic induction of the minimal EPO promoter could be seen in Kelly cells (Figure 3A) which we previously had not observed in Hep3B cells. ${ }^{18}$ Inspection of the $147 \mathrm{bp}$ fragment containing the 138 bp EPO promoter revealed a tandem dimeric repeat with two previously unreported putative HRE (Figure $3 \mathrm{~B}$ ). These putative HRE are highly conserved and locate close to WT1 and GATA binding sites (Online Supplementary Figure S4). In combination with the $5^{\prime}$ and $3{ }^{\prime}$ HRE enhancers, luciferase expression driven by this promoter fragment was induced 152-fold by hypoxia in this experimental series. Mutation of either promoter HRE (pHRE) 1 or pHRE2 significantly reduced hypoxic luciferase expression levels, whereas the effect on the 
A

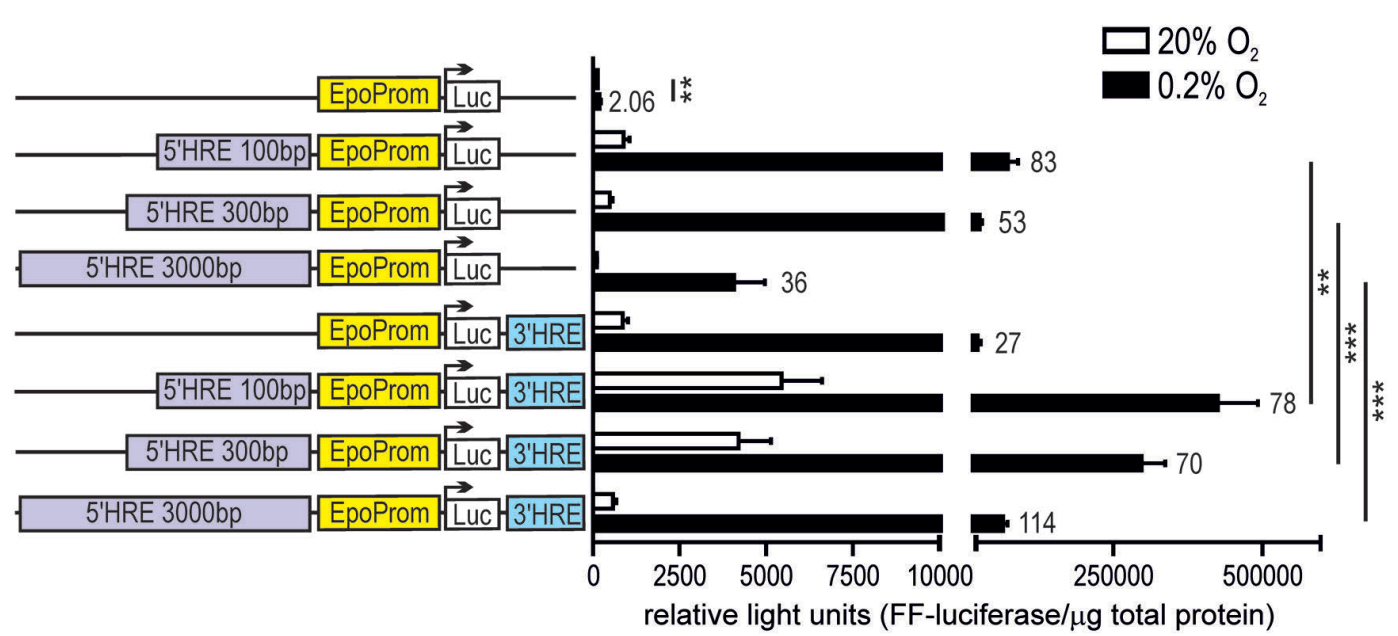

B $\stackrel{\text { pHRE1 }}{\longleftarrow}$

CCCCTGCTCTGACCCCGGGTGGCCCCTACCCCTGGCGACCCCTCACGCACACAGCCTCTCCCCCACCCCCACCC GCGCACGCACACATGCAGATAACAGCCCCGACCCCCGGCCAGAGCCGCAGAGTCCCTGGGCCACCCCGGCCGC $\overleftarrow{\text { pHRE2 }}$ TSS

C

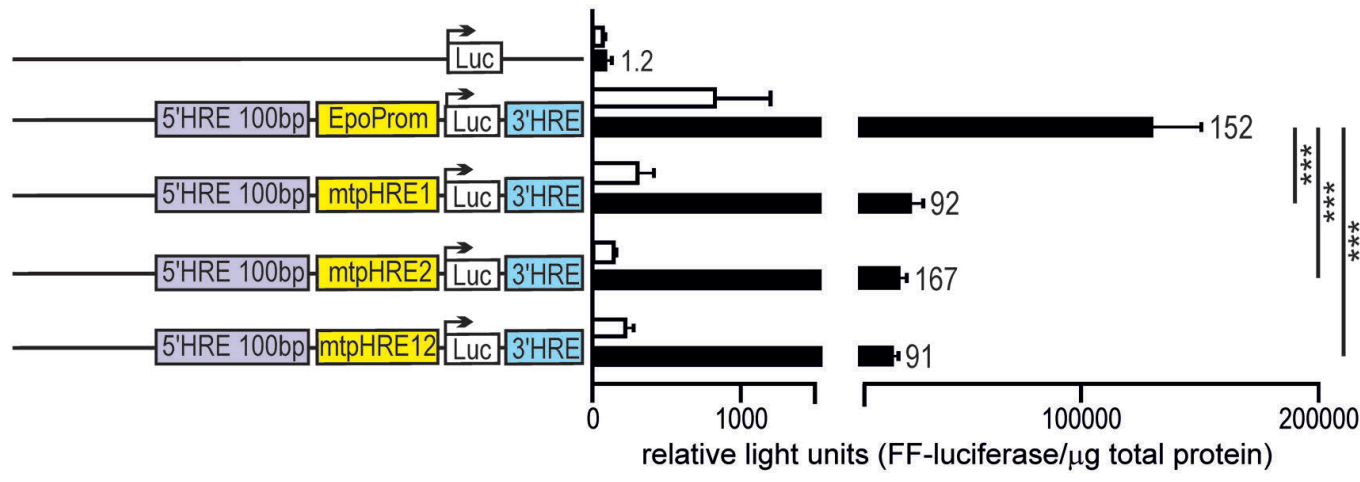

D

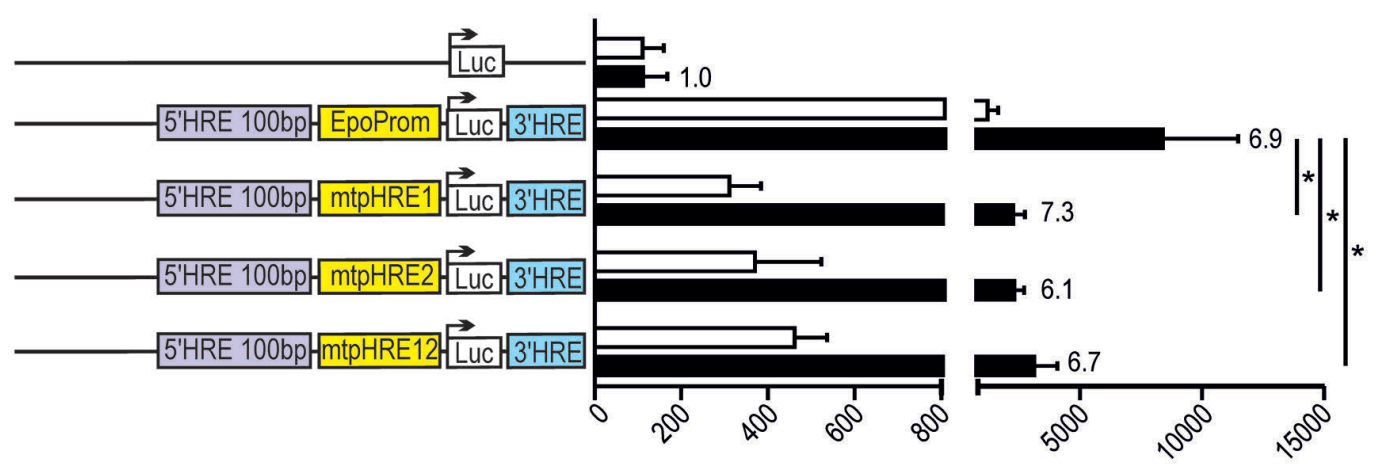

relative light units (FF-luciferase/ $\mu \mathrm{g}$ total protein)

Figure 3. EPO promoter-driven and hypoxia response elements (HRE)-enhanced luciferase reporter gene expression. Kelly (A and C) and Hep3B (D) cells were transiently transfected with the indicated reporter gene constructs and exposed for 24 hours to normoxic or hypoxic $\left(0.2 \% \mathrm{O}_{2}\right)$ conditions. Luciferase activities were normalized to the protein content and shown as mean+standard error of mean of six (A and C) or three (D) independent experiments. Numbers on the right of the bars indicate hypoxic induction factors. Student $t$-tests were used to statistically assess hypoxic EPO promoter activities (EpoProm, wild-type; mtpHRE, mutant) and the effects of combining the $5^{\prime}$ with the $3^{\prime}$ HRE. $* P<0.05$, $* * P<0.01$, $* * * P<0.001$. (B) Sequence of the 147 bp human EPO promoter fragment (starting 138 bp upstream of the transcription start site; TSS), indicating a conserved tandem dimeric repeat (underlined), each containing a putative promoter HRE (pHRE1 and pHRE2). 
A
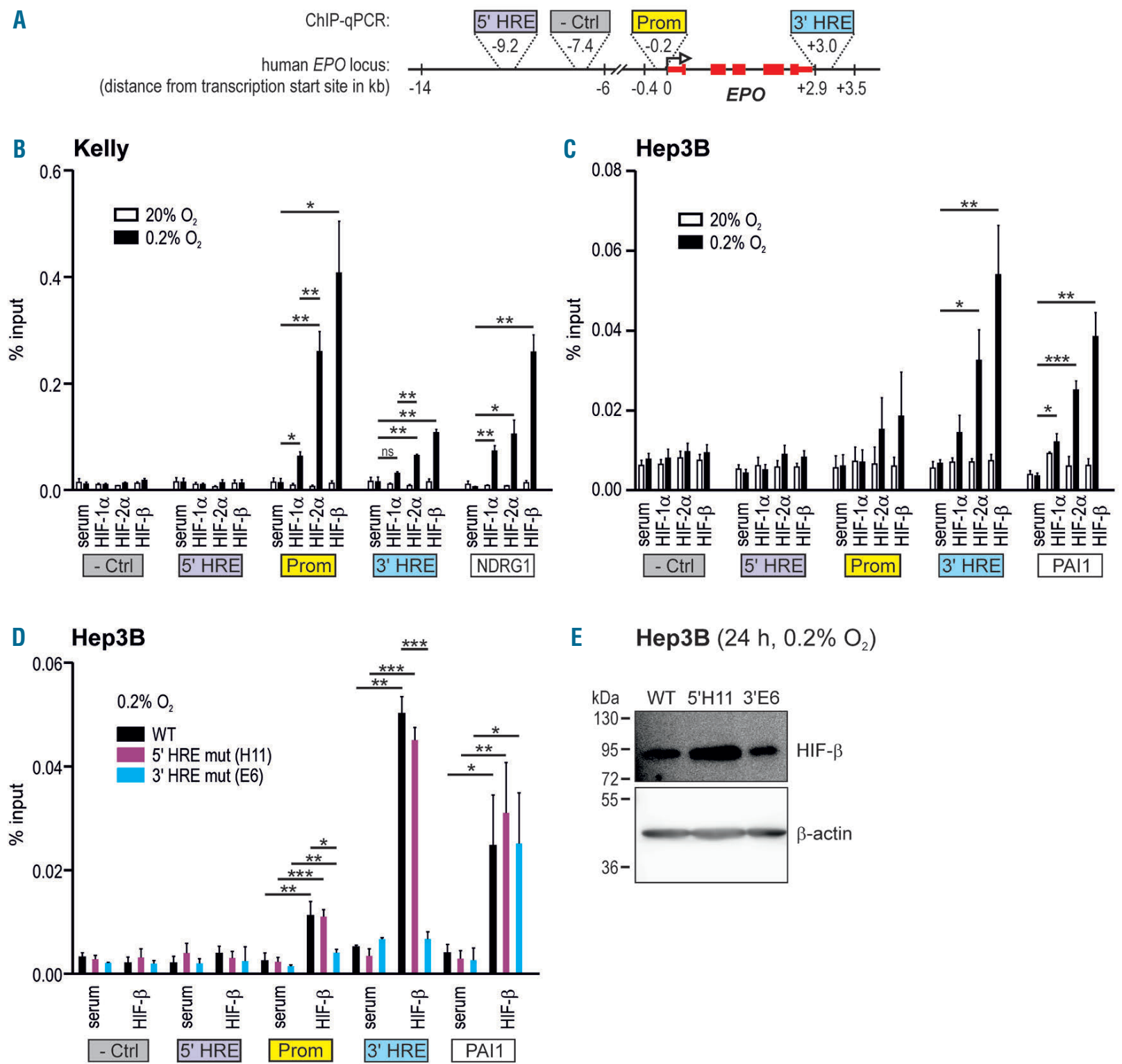

E Hep3B $\left(24 \mathrm{~h}, 0.2 \% \mathrm{O}_{2}\right)$

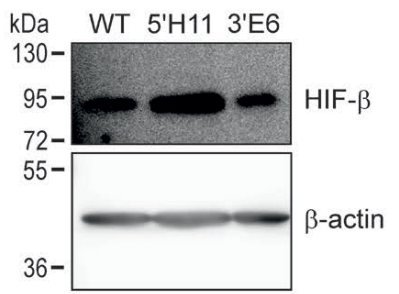

Figure 4. Hypoxia-inducible factor (HIF) binding to the EPO locus in $5^{\prime}$ or $3^{\prime}$ hypoxia response elements (HRE) mutant neuroblastoma and hepatoma cells. (A) Scheme depicting the regions of the EPO locus analyzed for HIF interaction by chromatin immunoprecipitation (ChIP), including the 5' and $3^{\prime}$ HRE, the minimal promoter and a negative (-Ctrl) control region devoid of any HIF binding. Kelly (B) and Hep3B (C) cells were exposed for 24 hours to normoxic or hypoxic $\left(0.2 \% \mathrm{O}_{2}\right.$ ) conditions, followed by ChIP using antibodies derived against HIF-1 $\alpha$, HIF- $2 \alpha$ or HIF- $\beta$, or a negative control serum. The promoter HRE of the established HIF target genes NDRG1 and PAl1 served as control for ChIP efficiency. The amount of co-precipitated DNA was determined by real-time quantitative (q) polymerase chain reaction (PCR) and displayed relative to input. (D) These experiments were repeated with hypoxic wild-type (WT), 5' or 3' HRE mutant Hep3B cells. Mean+standard error of mean of three (Kelly) or four (Hep3B) independent experiments are shown. Student $t$-tests were performed to statistically evaluate the difference between the hypoxic ChIP samples and hypoxic serum controls. $* P<0.05, * * P<0.01, * * * P<0.001$. (E) Immunoblot confirmation of similar HIF- $\beta$ protein levels in the hypoxic Hep3B subclones used above. $\beta$-Actin was used as loading and blotting control.

hypoxic induction factors was less conclusive (Figure 3C). Double pHRE1 and pHRE2 mutation did not further decrease reporter gene expression, suggesting that this tandem dimeric sequence in the $E P O$ promoter acts as a single HRE. Similar results were obtained with Hep3B cells (Figure 3D), though absolute as well as hypoxicallyinduced reporter gene levels were much lower than in Kelly cells.

Hypoxia-inducible factor interacts with the EPO promoter and the $3^{\prime}$, but not the $5^{\prime}$, hypoxia response element in neuronal cells

To directly analyze the interaction between HIF and the various HRE of the endogenous EPO locus, ChIP followed by GPCR experiments were performed. Because of the contribution of the promoter to the hypoxic activation of reporter gene expression observed above, we also included the proximal 5' region in these ChIP-qPCR experiments (Figure 4A). Unexpectedly, Kelly cells did not show any significant binding of the HIF subunits HIF- $1 \alpha$, HIF- $2 \alpha$ or HIF- $\beta$ to the 5' HRE, whereas a significant hypoxic increase in HIF- $2 \alpha /$ HIF- $\beta$ binding to the $3^{\prime}$ HRE could be detected (Figure 4B). Surprisingly, however, the strongest HIF interaction in hypoxic Kelly cells was observed with the $E P O$ promoter region, again with a preference for HIF$2 \alpha / \mathrm{HIF}-\beta$. In contrast, in hypoxic Hep3B cells the strongest 
HIF- $2 \alpha / \mathrm{HIF}-\beta$ interaction was found at the 3 ' HRE and only a weak interaction with the promoter region could be observed (Figure 4C). Similar findings had previously been reported for hypoxic HepG2 cells using ChIPsequencing, ${ }^{29}$ whereas non-Epo-producing cell lines did not show any HIF binding to the EPO locus (Online Supplementary Figure S5). To control for ChIP efficiency, the presence of DNA fragments containing the HRE of the HIF-1/2 target genes NDRG1 and PAI $1^{21,25}$ was quantified by qPCR in the same samples. HIF binding to the estab-
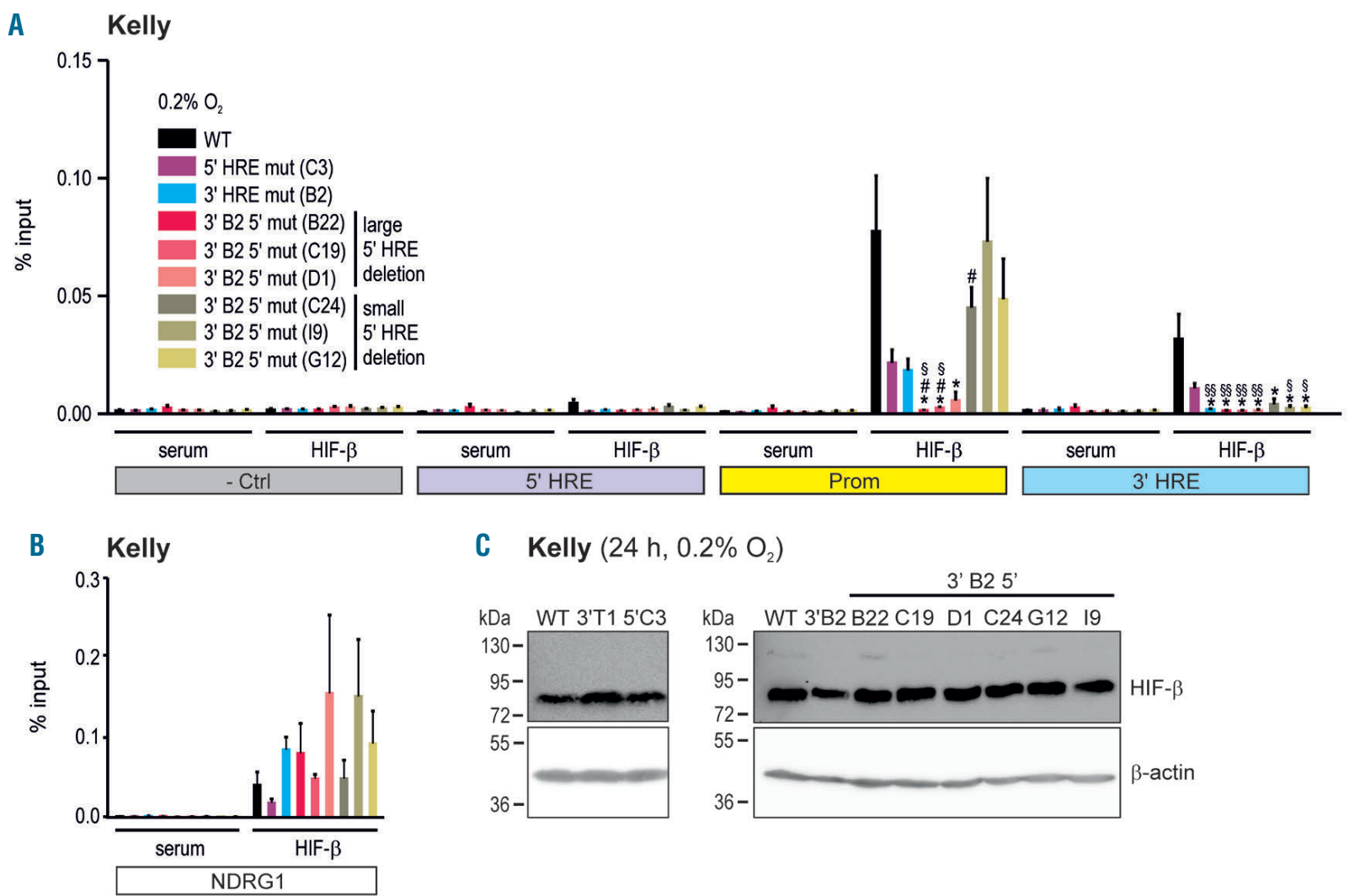

C Kelly $\left(24 \mathrm{~h}, 0.2 \% \mathrm{O}_{2}\right)$
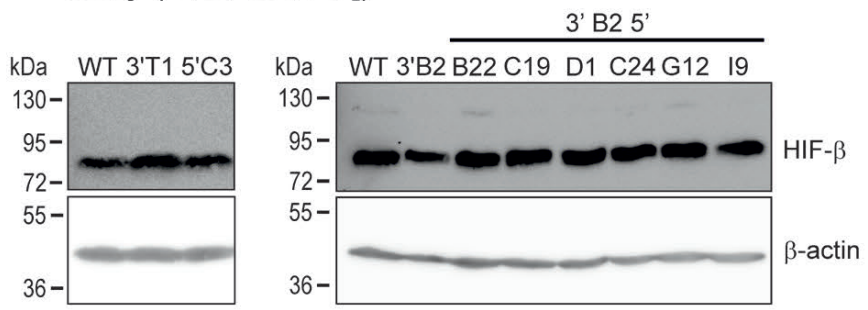

D
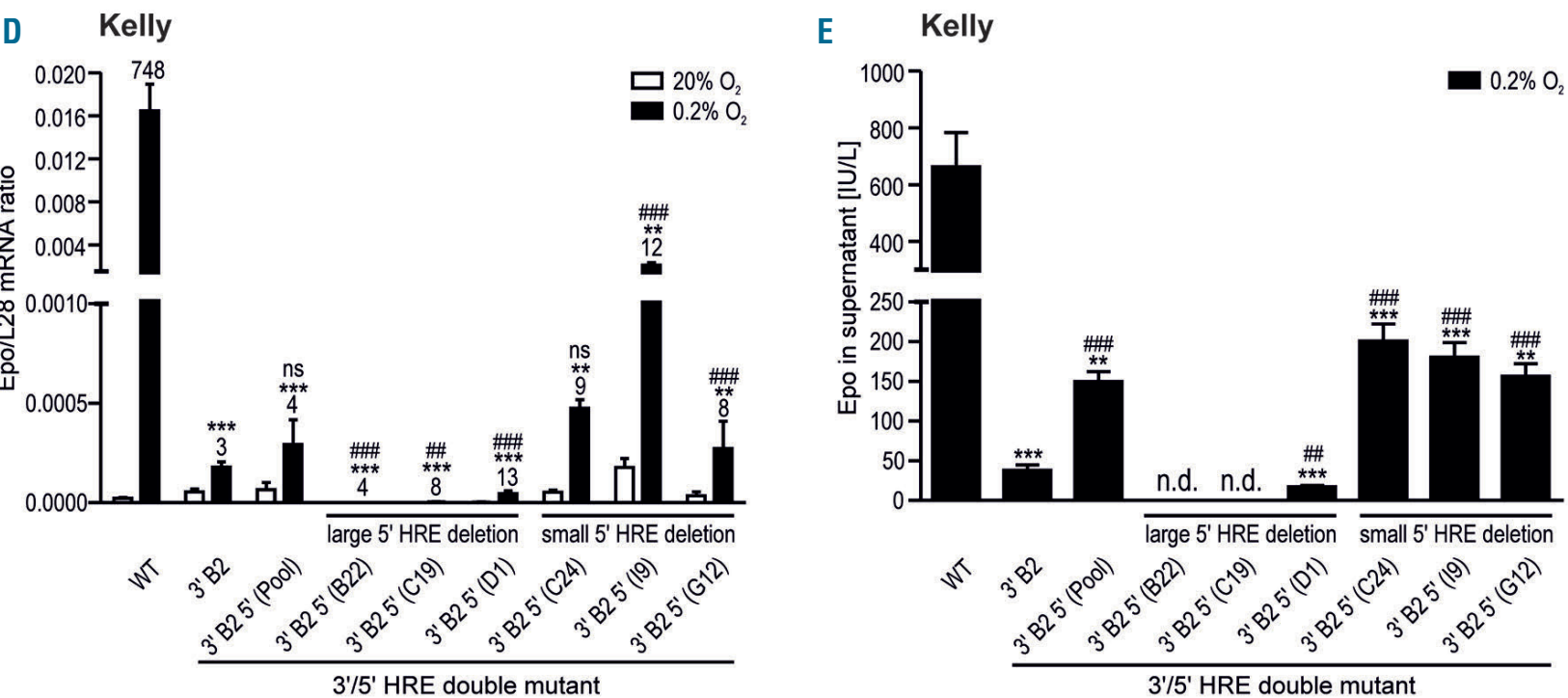

Figure 5. Hypoxia-inducible factor (HIF) binding to the EPO locus and Epo regulation in $3^{\prime} / 5^{\prime}$ hypoxia response elements (HRE) double-mutant neuroblastoma cells. (A and B) of hypoxic wild-type (WT) or mutant (as indicated) Kelly cells using antibodies derived against HIF- $\beta$ or negative control serum. The amount of co-precipitated DNA was determined by real-time quantitative polymerase chain reaction ((RT-qPCR) covering the indicated regions of the EPO locus (A) or the HRE of the NDRG1 control locus (B) and displayed relative to input. Data are shown as mean+standard error of mean of four independent experiments. Student $t$-tests were performed to statistically evaluate the difference to hypoxic WT ( ${ }^{*} P<0.05$ ) or $3^{\prime} \mathrm{B} 2\left({ }^{\#} P<0.05\right)$ or $5^{\prime} \mathrm{C} 3$ cells ( ${ }^{\$} P<0.05$, $\left.{ }^{\S s} P<0.01\right)$. (C) Immunoblot confirmation of similar HIF- $\alpha$ protein levels in the hypoxic Kelly subclones used above. $\beta$-Actin was used as loading and blotting control. (D and E) Epo production in WT, single $3^{\prime}$ B2 or double $3^{\prime}$ B2 5' HRE mutant Kelly cells exposed for 24 hours to normoxia or hypoxia $\left(0.2 \% \mathrm{O}_{2}\right)$ was measured by RT-qPCR on the mRNA level (D) or by ELISA on the protein level (E). Data are shown as mean+standard error of mean of 3-6 (D) or 5-10 (E) independent experiments. Student $t$-tests were used to statistically evaluate the difference to hypoxic WT $(* * P<0.01, * * * P<0.001)$ or 3 ' B2 cells $\left({ }^{* \#} P<0.01\right.$; ${ }^{\# \# \#} P<0.001$; ns: not significant; n.d.: not detectable). 
Kelly

$\square 20 \% \mathrm{O}_{2}$

$0.2 \% \mathrm{O}_{2}$

A

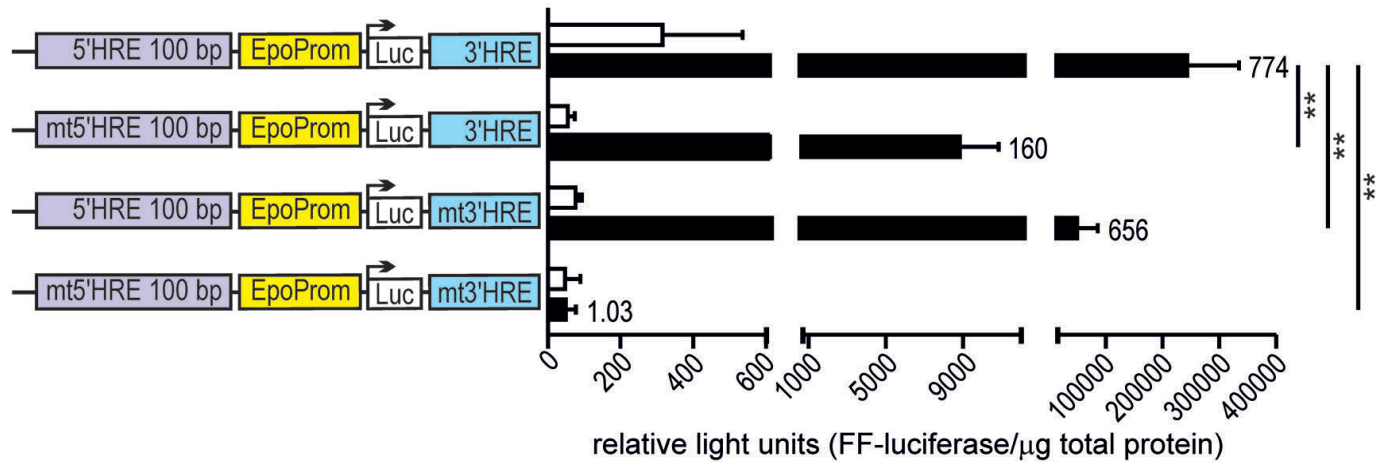

B

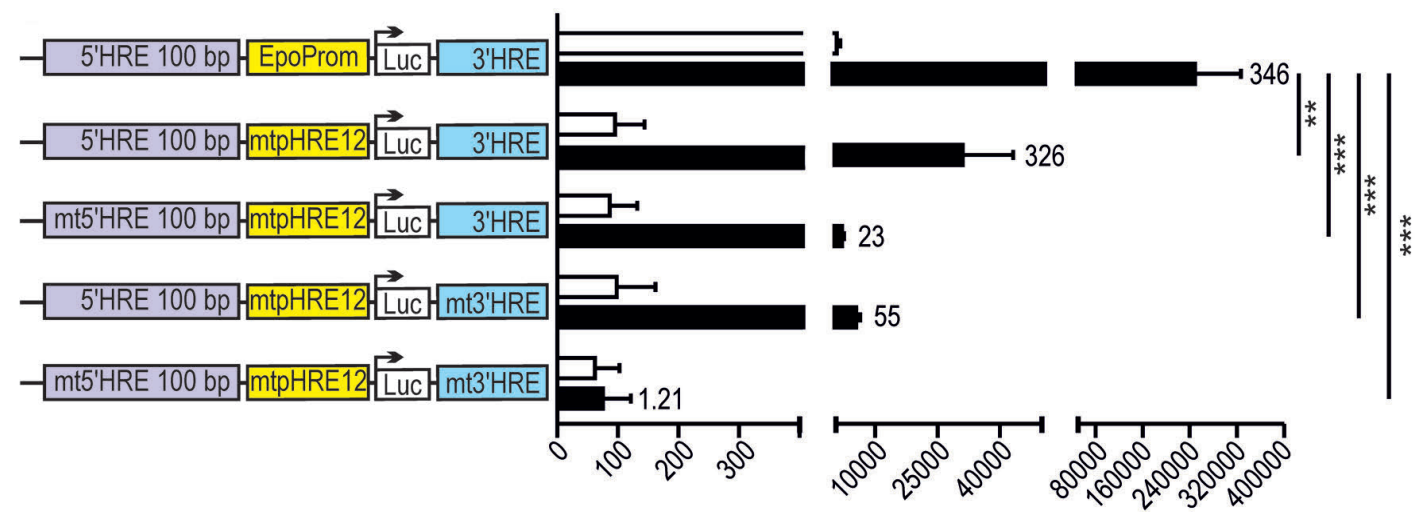

Hep3B

relative light units (FF-luciferase/ $\mu$ g total protein)

C

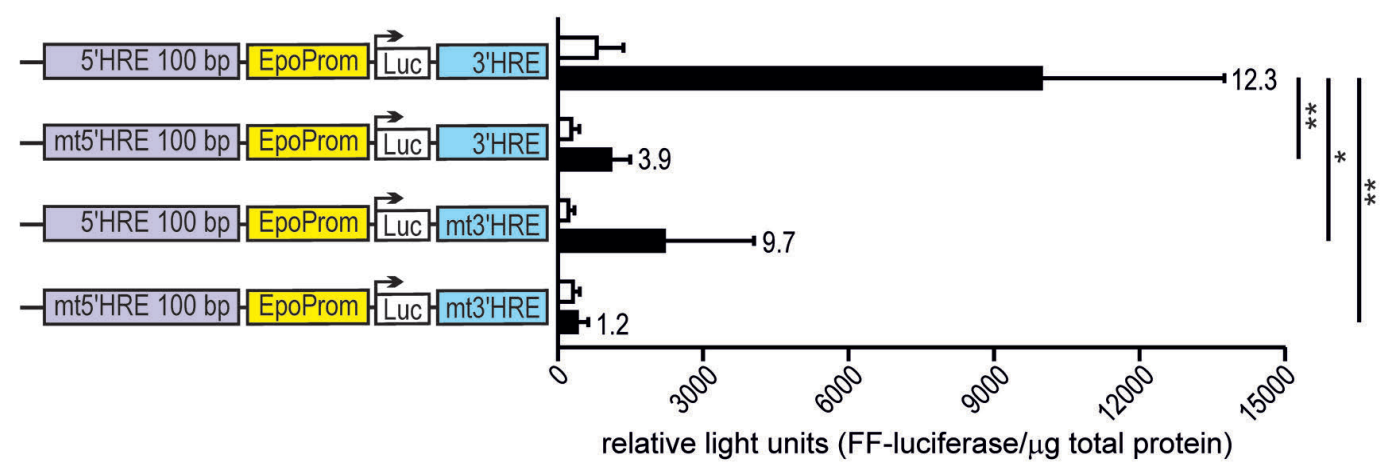

D

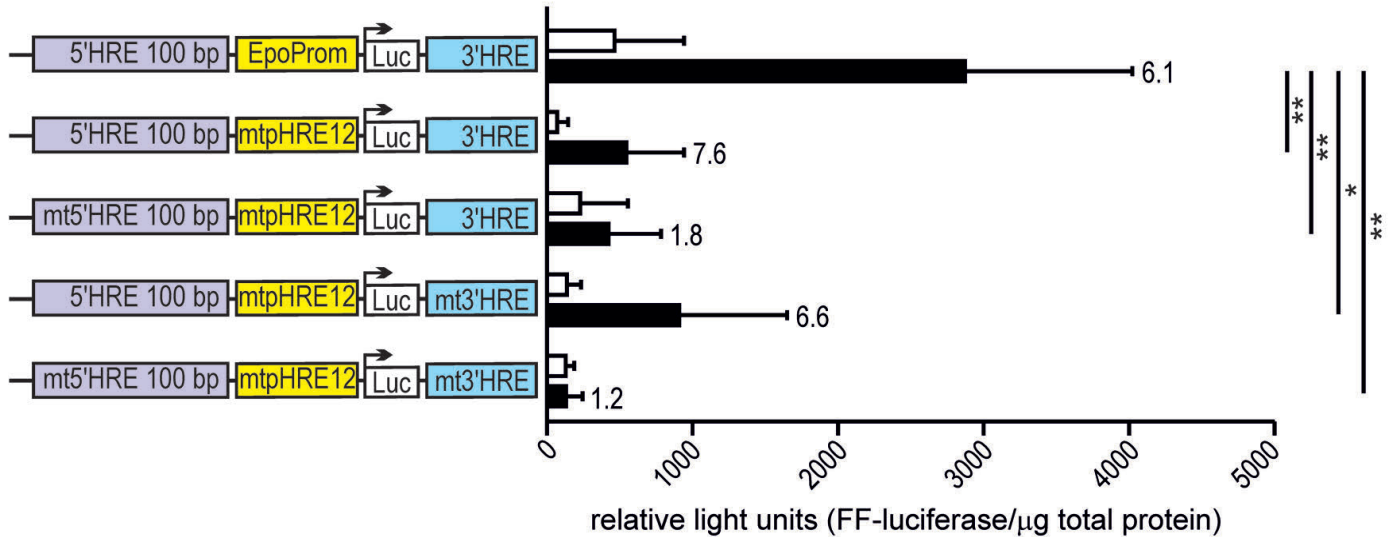

Figure 6. EPO promoter/enhancer-driven luciferase reporter gene expression following single and combined hypoxia response elements (HRE) mutations. Kelly (A and $B)$ and Hep3B (C and D) cells were transiently transfected with the indicated reporter gene constructs and exposed for 24 hours to normoxic or hypoxic $(0.2 \%$ $\mathrm{O}_{2}$ ) conditions. Luciferase activities were normalized to the protein content and shown as mean+standard error of mean of four independent experiments. Numbers on the right of the bars indicate hypoxic induction factors. Student t-tests were used to statistically assess hypoxic $E P O$ promoter activities. ${ }^{\star} P<0.05, * \star P<0.01$. $* * * P<0.001$. 
lished NDRG1 and PAI1 promoter HRE was comparable to the Epo HRE, and anti-HIF- $\beta$ antibodies precipitated roughly additive amounts of chromatin seen with the HIF$1 \alpha$ and HIF-2 $\alpha$ antibodies (Figures 4B and C).

\section{Functional distal 3 ' and 5 ' hypoxia response elements are required for remote control of hypoxia-inducible factor binding to the EPO promoter}

Because ChIP resolution is insufficient to detect the precise protein-DNA interaction site, we next wanted to confirm that HIF actually bound the core sequence of the investigated HRE. Therefore, Hep3B 3' and 5' mutant HRE subclones were exposed to hypoxia and used for ChIP with anti-HIF- $\beta$ antibodies to precipitate both HIF-1 and HIF-2. As expected, HIF bound the wild-type 3' HRE but did not interact with the mutant 3' HRE (Figure 4D). Of note, the 3' HRE mutation apparently also decreased the weak HIF interaction with the EPO promoter region. Consistent with its non-functionality in Hep3B cells, mutation of the 5' HRE did not influence HIF binding to any of the tested HRE (Figure 4D). Neither HIF- $\beta$ binding to the PAI1 control HRE (Figure 4D), nor HIF- $\beta$ protein levels (Figure 4E), were altered in these Hep3B subclones, confirming that HIF- $\beta$ expression is not generally affected by the $3^{\prime}$ and 5 ' HRE mutations, and that HIF- $\beta$ ChIP reliably detects HIF-DNA interactions.

To further investigate the unexpected inhibitory effect of the distal 3' HRE mutation on the HIF interaction with the proximal EPO promoter region in Hep3B cells, these experiments were repeated with Kelly $3^{\prime}$ and $5^{\prime}$ mutant HRE subclones. Intriguingly, the 3' HRE mutation (clone B2) not only completely abrogated the interaction between HIF and the 3' HRE, but also strongly decreased the interaction with the promoter region (Figure 5A). Moreover, the 5' HRE mutation (clone C3) similarly impaired HIF interaction with the 3' HRE and the promoter region (Figure $5 \mathrm{~A}$ ), while comparable HIF binding to the NDRG1 control HRE (Figure 5B) and HIF- $\beta$ protein levels (Figure 5C) could be detected in these mutant Kelly subclones.

\section{Large but not small deletions of the 5 ' hypoxia response element abrogate Epo induction in $3^{\prime} / 5^{\prime}$ hypoxia response element double-mutant neuronal cells}

Because there was residual HIF binding to the EPO promoter in the single $3^{\prime}$ and $5^{\prime}$ HRE mutant Kelly subclones, we wondered whether $3^{\prime} / 5^{\prime}$ HRE double mutations would lead to a further decrease in the HIF interaction with the EPO promoter. The introduction of a secondary mutation was rather inefficient and worked only in the B2 3' HRE mutant Kelly subclone. Deep sequencing of the PCR products derived from the mutant 5 ' HRE revealed 3 subclones with large (31 bp and $18 \mathrm{bp}$; varying ratios) and 3 subclones with small (1, 2 or $3 \mathrm{bp}$; biallelic) deletions (Online Supplementary Figure S6A). Despite some reduction in CAIX mRNA and HIF-1 $\alpha$ protein in the subclones containing the larger deletions, the double-mutant subclones did not show any major general differences in mRNA levels of the HIF target genes CAIX and LOXL2, or in hypoxic HIF-1 $\alpha$ and HIF-2 $\alpha$ protein levels (Online Supplementary Figure S6B-E).

In hypoxic Kelly cells, only the larger but not the smaller 5' HRE deletions further decreased HIF binding to the $E P O$ promoter in the $3^{\prime} / 5^{\prime}$ HRE double-mutant subclones (Figure 5A). The small core 5' HRE mutations partly reversed the inhibitory effect of the 3 ' HRE mutation on HIF promoter interaction. HIF- $\beta$ binding to the NDRG1 control HRE (Figure 5B), as well as HIF- $\beta$ protein levels (Figure 5C), remained at similar levels, confirming that HIF- $\beta$ expression is not generally affected in these Kelly subclones, and that HIF- $\beta$ ChIP reliably detects HIF-DNA interactions. Consistent with the ChIP data, the additional larger or smaller $5^{\prime}$ HRE deletions further decreased or partly reversed, respectively, Epo mRNA (Figure 5D) and protein (Figure 5E) levels in hypoxic 3' HRE mutant Kelly cells.

\section{The core hypoxia-inducible factor-binding sites of all EPO hypoxia response elements are required for hypoxic reporter gene expression}

To further dissect the relevance of the various EPO HRE, the conserved core HIF-binding sites were mutated (5'CGTG-3' to 5'-AAAG-3') in EPO promoter/enhancer-driven reporter gene constructs. Mutation of either the $5^{\prime}$ or the 3 ' HRE significantly reduced hypoxic reporter gene expression in Kelly cells, with the 5' HRE showing a stronger effect than the 3 ' HRE. Simultaneous mutation of both sites completely abrogated hypoxic reporter gene expression (Figure 6A). Despite the very weak activity of the minimal EPO promoter (Figure 3A), even the double mutation of the two EPO promoter HRE significantly reduced hypoxic reporter gene expression in these constructs (Figure 6B). Additional 5' or 3' HRE single or double mutations further reduced or abrogated, respectively, hypoxic reporter gene expression (Figure 6B).

In contrast to the endogenous $E P O 5^{\prime}$ and/or 3' HRE deletions by gene editing (see above), both HRE contribute to hypoxic $E P O$ promoter induction in exogenous reporter genes transfected into Hep3B cells (Figure 6C), as we have previously reported for these cells as well as for non-Epoproducing cells. ${ }^{18}$ Both absolute and hypoxically-induced reporter gene levels were much lower than in Kelly cells. Again, double mutation of the EPO promoter HRE significantly reduced hypoxic reporter gene expression, which could only be completely abolished when the $5^{\prime}$ and $3^{\prime}$ HRE were additionally mutated (Figure 6D).

\section{Discussion}

The data reported here reveal a complex and organ-specific interplay between various HRE at the EPO locus. The previously described mechanisms of $E P O$ regulation in hepatic cells were mostly confirmed by our experiments, including a strong functional dependence on the endogenous 3' HRE with a robust HIF interaction, and a complete lack of requirement for the endogenous 5' HRE despite a strong hypoxic enhancer function in exogenous reporter gene experiments. In neuronal cells, the endogenous 5' HRE seems to be as important as the $3^{\prime}$ HRE for hypoxic induction of $E P O$ gene expression, and the $5^{\prime}$ and 3' HRE co-operate in hypoxic enhancement of exogenous reporter gene expression, but the 5' HRE does not directly interact with HIF. In contrast to hepatic cells, where the $E P O$ promoter is only slightly bound by HIF and does not confer hypoxic reporter gene induction, ${ }^{18}$ in neuronal cells it is the EPO promoter that most strongly interacts with HIF, consistent with a weak hypoxic induction of reporter genes. EPO minimal promoter fragments spanning at least $-91 \mathrm{bp}$ upstream of the transcriptional start site have 
previously been shown to be hypoxia responsive in reporter gene experiments also in Hep3B cells. ${ }^{30,31}$

It is still not clear why we repeatedly found significant hypoxic promoter induction only in Kelly but not in Hep3B cells. Inspection of the minimal EPO promoter region revealed two potential HRE characterized by the presence of evolutionary conserved 5'-GCGTG-3' HIF binding motifs. Mutation of either of these two HRE in Kelly cells reduced both basal and hypoxia-inducible promoter activity enhanced by the 5' and 3' HRE. Tissue-specific transcriptional co-activators and/or co-repressors may be involved in the difference in hypoxic promoter activity and HIF binding between hepatic and neuronal cells. Indeed, a co-operative interaction with additional transcription factors binding in close proximity to HIF is typical for HRE and has also been found in other HIF target genes. ${ }^{21}$ While the ancillary $5^{\prime}$-CACA- 3 ' element ${ }^{11}$ is missing, its supportive function may be replaced by the neighboring DNA binding sites for GATA factors and the Wilms tumor gene (WT1) product, which are well-known to regulate the EPO promoter. $^{32-35}$ It has recently been shown that WT1 is itself hypoxia-inducible and restricted to neuroblastoma and kidney-derived cell lines, ${ }^{9,36}$ which might contribute to both hypoxia-inducible as well as tissue-specific EPO promoter activity. Alternatively, it is possible that binding of HIF to the promoter and/or transcriptional activation may be blocked by binding of an as yet unknown tissue-specific factor in Hep3B cells. Of note, we have previously shown that ATF/CREB family members are able to directly interact with the HRE core motif, ${ }^{37}$ and it may be that such an interaction also occurs at the promoter HRE.

How can it be explained that a conserved HRE consensus core sequence, including the ancillary element, is functionally relevant for hypoxic induction of gene expression but not directly bound by HIF, as appears to be the case for the EPO 5' HRE? We have previously shown for PAG1, another HIF-2 target gene, that a single distal $82 \mathrm{~kb} 5$ ' HRE resides in an isolated DNA region, bound by many additional transcription factors, and forms multiple chromatin loops both locally and over a long distance with the promoter region. ${ }^{21}$ While in this case HIF-2 $\alpha$ did interact with the HRE, neither hypoxia nor the presence of HIF was needed for the long-range chromatin interaction with the promoter region. Only the presence of the core 5'-ACGTG-3' HIF binding DNA sequence was required to maintain this interaction, suggesting that preformed chromatin loops enable oxygen-regulated conditional gene regulation. This model has subsequently been confirmed for many other HIF target genes by genomewide approaches. ${ }^{38,39}$ Therefore, the EPO 5' HRE might well be functionally required for hypoxia-inducible gene expression by maintaining a constitutive chromatin architecture that supports promoter activity in a cell type-specific manner. The finding that only additional large but not small 5' HRE deletions fully abrogated endogenous Epo induction and HIF:promoter interaction in $3^{\prime}$ HRE mutant Kelly cells suggests that, like in the case of the PAG1 gene, additional transcription factors bind close to the consensus HRE sequence and are involved in chromatin looping and trans-activation of the EPO promoter. We still have no explanation why a small 5' HRE deletion alone inhibited HIF-promoter interaction, but in combination with a $3^{\prime}$ HRE mutation partially rescued the inhibitory effect of the 3' HRE mutation. Nonetheless, it is without precedent that the extended 5' HRE strongly cis-enhanced HIF binding to the promoter and 3' HRE.

The differences between Epo-producing hepatic and neuronal cells raise the question of how EPO is regulated in renal Epo-producing (REP) cells, the main source of circulating Epo. The overlap of neuronal markers with genetically tagged mouse REP cells ${ }^{8,9}$ suggests that Kelly cells may represent a better model than hepatoma cells to recapitulate human oxygen-regulated EPO gene expression in the kidney, at least concerning the enigmatic 5' regulatory regions. Indeed, deletion of the endogenous $3^{\prime}$ HRE in the mouse suppressed only hepatic but not renal Epo expression, suggesting the presence of one or more additonal HRE in REP cells. ${ }^{17}$ Consistently, deletion of a 17.4 to $-3.6 \mathrm{~kb}$ Epo 5' region in transgenic mouse models abrogated Epo gene expression specifically in REP cells whereas it was dispensable for Epo expression in the brain. ${ }^{31}$ Mutation of the mouse $-8.3 \mathrm{~kb} 5$ ' HRE (corresponds to the human $-9.2 \mathrm{~kb} 5^{\prime} \mathrm{HRE}$ ) within this Epo $5^{\prime}$ region did not abrogate transgenic Epo gene expression in the kidney (brain was not analyzed) and a minimal $0.3 \mathrm{~kb}$ fragment containing this 5' HRE was not sufficient to drive transgenic GFP expression in the mouse kidney. ${ }^{31}$ Our results on the co-operation between $5^{\prime}, 3^{\prime}$ and promoter HRE in neuronal and hepatic cell lines may help to explain these findings in transgenic mice: while the deletion of the 3' HRE in the liver is sufficient to abrogate hypoxic Epo expression, only the combined deletion of the extended 5' and the minimal 3' (and maybe the promoter) HRE may affect Epo expression in the kidney.

Altogether, these results demonstrate that several HRE are involved in oxygen-regulated EPO gene expression. While in the liver the 3' HRE is both necessary and sufficient, in the kidney the $3^{\prime}$ HRE is not essential and a $5^{\prime}$ HRE acts in concert with additional long-range enhancer elements, and probably local chromatin structure. Although transgenic mouse models are still lacking, our results suggest that in the brain, both of these distal HRE functionally co-operate with HIF binding to promoter HRE. Our results further illustrate that not all HRE act in a canonical way by directly binding HIF, and that HREpromoter co-operations in oxygen-regulated gene expression need to be analyzed in a cell type-specific context and cannot be generalized based on the results obtained with a single cell line. Similar results have recently been reported for the MALAT1 locus, expressing a lncRNA which is strongly hypoxia-inducible, ${ }^{40}$ where HIF-dependent and independent long-range interactions contribute to hypoxia-inducibility in a cell-type specific manner. ${ }^{41}$ Finally, our findings are also relevant for disease-associated polymorphisms that either create or delete potential $\mathrm{HRE}^{26,42,43}$ and may therefore interfere with long-range chromatin interactions.

\section{Acknowledgments}

The authors wish to thank J. Fandrey for providing cells, $K A$ Nolan for critical comments and R. Hunkeler for technical assistance.

\section{Funding}

This work was supported by the National Centre of Competence in Research "Kidney.CH" and the Swiss National Science Foundation (310030_184813 to RHW), Cancer Research UK (A416016 to DR $\bar{M})$ and the National Institute for Health Research (NIHR-RP-2016-06-004 to DRM). 


\section{References}

1. Wenger RH, Hoogewijs D. Regulated oxygen sensing by protein hydroxylation in renal erythropoietin-producing cells. Am J Physiol Renal Physiol. 2010;298(6):F12871296.

2. Wenger RH, Kurtz A. Erythropoietin. Compr Physiol. 2011;1:1759-1794.

3. Tan CC, Eckardt KU, Ratcliffe PJ. Organ distribution of erythropoietin messenger RNA in normal and uremic rats. Kidney Int. 1991; 40(1):69-76.

4. Marti HH, Wenger RH, Rivas LA, et al. Erythropoietin gene expression in human, monkey and murine brain. Eur J Neurosci. 1996;8(4):666-676

5. Yasuda Y, Masuda S, Chikuma M, Inoue K, Nagao M, Sasaki R. Estrogen-dependent production of erythropoietin in uterus and its implication in uterine angiogenesis. J Biol Chem. 1998;273(39):25381-25387.

6. Magnanti M, Gandini O, Giuliani L, et al. Erythropoietin expression in primary rat Sertoli and peritubular myoid cells. Blood. 2001;98(9):2872-2874.

7. Maxwell PH, Osmond MK, Pugh CW, et al. Identification of the renal erythropoietinproducing cells using transgenic mice. Kidney Int. 1993;44(5):1149-1162.

8. Obara N, Suzuki N, Kim K, Nagasawa T, Imagawa S, Yamamoto M. Repression via the GATA box is essential for tissue-specific erythropoietin gene expression. Blood. 2008;111(10):5223-5232

9. Imeri F, Nolan KA, Bapst AM, et al. Generation of renal Epo-producing cell lines by conditional gene tagging reveals rapid HIF-2 driven Epo kinetics, cell autonomous feedback regulation, and a telocyte phenotype. Kidney Int. 2019;95(2):375-387.

10. Kapitsinou PP, Liu Q, Unger TL, et al. Hepatic HIF-2 regulates erythropoietic responses to hypoxia in renal anemia. Blood. 2010;116(16):3039-3048.

11. Wenger RH, Stiehl DP, Camenisch G. Integration of oxygen signaling at the consensus HRE. Sci STKE. 2005;2005(306):re12.

12. Semenza GL, Dureza RC, Traystman MD, Gearhart JD, Antonarakis SE. Human erythropoietin gene expression in transgenic mice: multiple transcription initiation sites and cis-acting regulatory elements. Mol Cell Biol. 1990;10(3):930-938.

13. Semenza GL, Nejfelt MK, Chi SM, Antonarakis SE. Hypoxia-inducible nuclear factors bind to an enhancer element located $3^{\prime}$ to the human erythropoietin gene. Proc Natl Acad Sci U S A. 1991;88(13): 5680-5684

14. Madan A, Lin C, Hatch SLI, Curtin PT. Regulated basal, inducible, and tissue-specific human erythropoietin gene expression in transgenic mice requires multiple cis DNA sequences. Blood. 1995;85(10): 2735-2741

15. Köchling J, Curtin PT, Madan A. Regulation of human erythropoietin gene induction by upstream flanking sequences in transgenic mice. Br J Haematol. 1998;103(4):960-968.

16. Semenza GL, Wang GL. A nuclear factor induced by hypoxia via de novo protein synthesis binds to the human erythropoietin gene enhancer at a site required for transcriptional activation. Mol Cell Biol. 1992;12(12):5447-5454

17. Suzuki N, Obara N, Pan X, et al. Specific contribution of the erythropoietin gene 3 enhancer to hepatic erythropoiesis after late embryonic stages. Mol Cell Biol. 2011;31 (18):3896-3905

18. Storti F, Santambrogio S, Crowther L, et al. A novel distal upstream hypoxia response element regulating oxygen-dependent erythropoietin gene expression. Haematologica. 2014;99(4):e45-e48.

19. Stolze I, Berchner-Pfannschmidt U, Freitag $P$, et al. Hypoxia-inducible erythropoietin gene expression in human neuroblastoma cells. Blood. 2002:100(7):2623-2628.

20. Goldberg MA, Glass GA, Cunningham JM, Bunn HF. The regulated expression of erythropoietin by two human hepatoma cell ines. Proc Natl Acad Sci U S A. 1987;84(22):7972-7976

21. Schörg A, Santambrogio S, Platt JL, et al. Destruction of a distal hypoxia response element abolishes trans-activation of the PAG1 gene mediated by HIF-independent chromatin looping. Nucl Acids Res. 2015;43(12):5810-5823.

22. Harms DW, Quadros RM, Seruggia D, et al Mouse genome editing using the CRISPR/Cas system. Curr Protoc Hum Genet. 2014:83:15

23. Wollenick $\mathrm{K}, \mathrm{Hu} \mathrm{J}$, Kristiansen $\mathrm{G}$, et al. Synthetic transactivation screening reveals ETV4 as broad coactivator of hypoxiainducible factor signaling. Nucl Acids Res. 2012;40(5):1928-1943

24. Bradford MM. A rapid and sensitive method for the quantitation of microgram quantities of protein utilizing the principle of proteindye binding. Anal Biochem. 1976;72:248254

25. Schödel J, Oikonomopoulos S, Ragoussis J, Pugh CW, Ratcliffe PJ, Mole DR. High-resolution genome-wide mapping of HIF-binding sites by ChIP-seq. Blood. 2011 117(23):e207-217.

26. Schödel J, Bardella C, Sciesielski LK, et al. Common genetic variants at the 11q13.3 renal cancer susceptibility locus influence binding of HIF to an enhancer of cyclin D1 expression. Nat Genet. 2012;44(4):420-425.

27. Wenger RH, Kvietikova I, Rolfs A Camenisch G, Gassmann M. Oxygen-regulated erythropoietin gene expression is dependent on a $\mathrm{CpG}$ methylation-free hypoxia-inducible factor-1 DNA-binding site. Eur J Biochem. 1998;253(3):771-777.

28. Stiehl DP, Bordoli MR, Abreu-Rodríguez I, et al. Non-canonical HIF-2 $\alpha$ function drives autonomous breast cancer cell growth via an AREG-EGFR/ErbB4 autocrine loop. Oncogene. 2012;31(18):2283-2297.

29. Smythies JA, Sun M, Masson N, et al.
Inherent DNA-binding specificities of the HIF- $1 \alpha$ and HIF- $2 \alpha$ transcription factors in chromatin. EMBO Rep. 2019;20(1).

30. Blanchard KL, Acquaviva AM, Galson DL Bunn HF. Hypoxic induction of the human erythropoietin gene: cooperation between the promoter and enhancer, each of which contains steroid receptor response elements. Mol Cell Biol. 1992;12(12):5373-5385

31. Hirano I, Suzuki N, Yamazaki S, et al. Rena anemia model mouse established by transgenic rescue with an erythropoietin gene lacking kidney-specific regulatory elements. Mol Cell Biol. 2017;37(4):e00451-00416.

32. Imagawa $S$, Yamamoto $M$, Miura $Y$ Negative regulation of the erythropoietin gene expression by the GATA transcription factors. Blood. 1997;89(4):1430-1439.

33. Imagawa S, Suzuki N, Ohmine K, et al GATA suppresses erythropoietin gene expression through GATA site in mouse erythropoietin gene promoter. Int J Hematol. 2002;75(4):376-381.

34. Dame C, Sola MC, Lim KC, et al. Hepatic erythropoietin gene regulation by GATA-4. J Biol Chem. 2004:279(4):2955-2961.

35. Dame C, Kirschner KM, Bartz KV, Wallach T, Hussels CS, Scholz H. Wilms tumor suppressor, Wt1, is a transcriptional activator of the erythropoietin gene. Blood. 2006; 107(11):4282-4290

36. Krueger K, Catanese L, Sciesielski LK, Kirschner KM, Scholz H. Deletion of an intronic HIF-2 $\alpha$ binding site suppresses hypoxia-induced WT1 expression. Biochim Biophys Acta Gene Regul Mech. 2019; 1862(1):71-83

37. Kvietikova I, Wenger RH, Marti $\mathrm{HH}$ Gassmann M. The transcription factors ATF-1 and CREB-1 bind constitutively to the hypoxia-inducible factor-1 (HIF-1) DNA recognition site. Nucl Acids Res. 1995;23(22): 4542-4550

38. Platt IL, Salama R, Smythies J, et al. Capture$C$ reveals preformed chromatin interactions between HIF-binding sites and distant promoters. EMBO Rep. 2016:17(10):1410-1421.

39. Niskanen H, Tuszynska I, Zaborowski R, et al. Endothelial cell differentiation is encompassed by changes in long range interaction between inactive chromatin regions. Nucl Acids Res. 2018;46(4):1724-1740.

40. Lelli A, Nolan KA, Santambrogio S, et al. Induction of long noncoding RNA MALAT1 in hypoxic mice. Hypoxia (Auckl). 2015;3:45-52

41. Stone JK, Kim JH, Vukadin L, et al. Hypoxia induces cancer cell-specific chromatin interactions and increases MALAT1 expression in breast cancer cells. J Biol Chem. 2019; 294(29):11213-11224.

42. Grampp S, Platt JL, Lauer V, et al. Genetic variation at the 8q24.21 renal cancer susceptibility locus affects HIF binding to a MYC enhancer. Nat Commun. 2016;7:13183.

43. Grampp S, Schmid V, Salama R, et al Multiple renal cancer susceptibility polymorphisms modulate the HIF pathway. PLoS Genet. 2017;13(7):e1006872. 